\title{
Structure and Development of Management Information System in Manufacturing Enterprises
}

\author{
Weimei Zhang \\ School of Business, Hunan City University ,Yiyang City, Hunan, China,413000 \\ Central South University of Forestry and Technology, Changsha, China,410002 \\ zhweimei@126.com.cn,
}

Keywords: Management information system, Structure, Manufacturing enterprise.

\begin{abstract}
Under the drive of the booming development of information technology, some manufacturing enterprises construct management information system (MIS) to acquire competitive advantages. This research was conducted to determine the structure and development of management information system in manufacturing Enterprises. Generally speaking, MIS in manufacturing enterprises mainly consists of sub-system of production and manufacture, sub-system of marketing, sub-system of materials management, sub-system of finance and sub-system of human resources.
\end{abstract}

\section{Introduction}

Creation and development of information technology has given birth to such new types of electronic information products manufacturing industry as computer. It has also brought about a series of revolutionary changes in the production means and operation philosophy of such traditional manufacturing industry as furniture, machinery and metallurgy through penetration and exposure ${ }^{[1]}$. Informatization has turned to be a general trend in development of the current global manufacturing industry. It has become a fundamental guarantee to develop the traditional manufacturing industry and an important measure taken to respond to the economic globalization tendency. As far as the manufacturing enterprises are concerned, in order for them to seek for survival and development in the fierce market competition, it is a must to increase their management efficiency ${ }^{[2]}$. Information industry not only itself has unlimited development space, but also infiltration and influence the manufacturing industry. So, it naturally becomes a necessary choice to apply modern information technology to set up Management Information System (MIS) of enterprises. This study gives the conception and functions of MIS in manufacturing enterprises. And propose the structure and development method of management information system in manufacturing Enterprises.

\section{Definition and basic functions of management information system in manufacturing enterprises}

In order to meet with the demand of manufacturing enterprise managers on information, the management information system needs to finish a large amount data or information processing work. Its basic functions may be summarized as the following five ones. 
Collection of Data. Data can only become useful information after being processed. The source of data can be classified into two kinds, namely, primary data and secondary data. If the data are directly accepted and collected in the very place where the data appear, this kind of data is called primary data, such as product inventory record and on-spot management record, etc. Collection of secondary data means collection of data which have been recorded in the media and which have been disconnected from the entity described both in terms of time and space. Data collected from the report forms of manufacturing enterprises are also included.

Storage of Data. Management information system has to possess the function of storing information. Otherwise, it is neither likely to break through limitations of time and space nor play the role of providing information support in decision making. The information storage issue to be considered by manufacturing enterprises includes volume of storage, information format, storage mode, application mode, storage time, security and secrecy, etc.

Processing Information. There are a variety of categories in information processing. Considering processing in itself, information processing can be classified into the two major categories of numeric calculation and nonnumeric processing. Numeric calculation includes simple arithmetic and algebraic operation, calculation and checking of all statistical magnitude in mathematical statistics, all optimum algorithm in operations research and simulation prediction method, etc. Nonnumeric data processing includes sequencing, merger, assortment and word processing, etc.

Transfer of Information. Information transfer is not simply an issue of transfer. The manager and the planner of an information system have to take full account of the factors of category, volume, frequency and reliability requirement of information to be transferred. In the actual work, information transfer is usually connected with information storage. Scattered storage of information may reduce the amount of information transfer. Nevertheless, scattered storage of information may also bring about a series of storage management issues, such as, security and consistency, which are difficult to be resolved. Concentrated storage of information may resolve the issue of storage at ease, but the burden of information transfer will be largely increased. Thus, the working staff have to make a choice between the balance and rationality of the two modes of information storage.

Information Providing. Providing means is an interface between management information system and its manager and is determined by the two aspects of information condition and condition of information user to be provided.

All the above listed are the five basic functions of management information system in manufacturing enterprises. In an actual operating management information system, the mechanisms playing functions are extremely different and the priority to be considered in design also differs with different systems. Nonetheless, any information system has to be equipped with necessary equipment to play all these five basic functions.

\section{Structure of management information system in manufacturing enterprises}

The typical functions of a manufacturing enterprise comprise of production and manufacture, marketing and market, finance and accounting, materials management and human resources. Therefore, based on the management function, the management 
information system in manufacturing enterprises is constituted by the following subsystems.

The System of Production and Manufacturing Information. The function of production and manufacture information system consists of production design and manufacture, planning of production equipment, task scheduling and running, quality control and checkout. In the sub-system of production and manufacture, the typical business processing contains manufacture order, assembly order, end product order, waste products order and working hours order. Operational control requires to make a comparison between the actual progress and the plan and to find out the bottleneck ${ }^{[4]}$. Management control calls for a generalized report to reflect the performance alteration of scheduled plan, unit cost and working hours in the whole plan. Strategic management contains selection of the manufacture method and all kinds of automation programs.

The System of Marketing Information. The function of marketing information system usually consists of sales and promotion of products as well as all activities in after-sale service. The business processing includes sales order and promotion order. Operational control contains all programs in employing and training sales personnel, working out a sales plan and promotion of products as well as a periodical analysis of technical area, products and sales volume of customers. Management control involves a comparison between the general achievement and the market plan, which requires the data concerning customers, competitors, competitive products and sales force. Strategic management includes pioneering of a new market and strategy of the new market and the information it uses contains customer analysis, competitor analysis, customer survey information, income forecasting and technical forecasting.

The System of Materials Management Information. Materials management information system consists of purchase, taking delivery of goods, inventory control and granting of products. The data in business processing include purchase of goods, application, purchase order, processing order, report of taking delivery, inventory ticket and bill of lading. The operational control requires to make a comparison between the actual material supply and the plan and make an analysis report concerning inventory level, purchase cost, delivery from storage and inventory turnover. Management control information contains comparison between the planned inventory and the physical inventory, costs of outsourcing, stockout and inventory carry rate. Strategic management mainly involves new material supply strategy, the new policy for suppliers and information with regards to the new supply program and new technology.

The System of Financial and Accounting Information. The financial and accounting information system consists of collection management, cash management and fund raising, standard for working out a financial statement, budgeting and assortment and analysis of cost data. The business processing contains application for buying or selling on credit, sales, making a bill, voucher of receiving an account, voucher of payment, check, transfer slip, ledger and share transfer. Operational control uses daily statement, exceptional case report, delay disposal report and report of untreated matters. Management control mainly uses the information of financial resource cost, cost of accounting data processing and error rate. Strategic management is mainly to ensure long-term strategic planning of adequate capital, long-term tax 
accounting policy for reducing tax revenue impact and planning of cost accounting and budgeting system.

The System of Human Resources. The function of human resource information system contains personnel employment, training, assessment record, wages and termination of service. The business processing contains recruitment condition, training introduction, basic employee information, wages alteration, working hours, welfare and notice of termination of service. The operational control contains completion of recruitment, training, termination of service, alteration of wages and of issuing of welfare. The management control mainly makes a comparison between the actual condition and the plan. The reports and results are used to account for the number of on-post workers, recruitment expense, constitution of technical expertise, wages payable, distribution of wage rate and whether the policy complies with the government employment policy. Human resource strategic plan includes evaluation on all kinds of strategic plans, such as, recruitment, wages, training, welfare and performance evaluation. These strategies will ensure whether an organization is able to acquire the human resources required for fulfillment a strategic objective. Strategic management also contains an analysis of employment system, educational condition, alteration of local wage rate and the personnel recruited and retained.

\section{Conclusions}

It becomes a necessary choice to apply modern information technology to set up MIS of manufacturing enterprises. Generally speaking, MIS in manufacturing enterprises mainly consists of sub-system of production and manufacture, sub-system of marketing, sub-system of materials management, sub-system of finance and subsystem of human resources.

\section{Acknowledgement}

This study was financially supported by Humanities and Social Sciences project of Ministry of Education of China (NO.12YJA630029) and project of Central South University of Forestry \&Technology (NO.11YY010).

\section{References}

[1] Z. Chu, 2003. Research on application of information system in human resource management. Jiangsu Commercial Forum, 6: 77-78.

[2] C.L. Dong, and S.S. Guo, 2008. The research of ERP reconfigurable mode based on the theory of evolution. Manuf. Autom, J., 6: 15-18.

[3] H. Yang, 2003. Research and development of key technology in manufacturing informatization. Manuf. Inform. Eng. China, 6: 4-7.

[4] S. Zhang, 2003. Where is the way out for informatization of manufacturing industry. Manuf. Inform. Eng. China, 8: 4-9. 